\title{
Predicting Bond Strength of Steel Reinforcement in Self-Compacting Concrete (SCC) Using Adaptive Neuro-Fuzzy Inference System (ANFIS)
}

\author{
Ngudiyono*, Jauhar Fajrin, I Nyoman Merdana, Fathmah Mahmud \\ Department of Civil Engineering, Faculty of Engineering, University of Mataram, Mataram, Indonesia
}

Received June 14, 2021; Revised July 13, 2021; Accepted August 22, 2021

\section{Cite This Paper in the following Citation Styles}

(a): [1] Ngudiyono, Jauhar Fajrin, I Nyoman Merdana, Fathmah Mahmud, "Predicting Bond Strength of Steel Reinforcement in Self-Compacting Concrete (SCC) Using Adaptive Neuro-Fuzzy Inference System (ANFIS)," Civil Engineering and Architecture, Vol. 9, No. 6, pp. 1717-1726, 2021. DOI: 10.13189/cea.2021.090605.

(b): Ngudiyono, Jauhar Fajrin, I Nyoman Merdana, Fathmah Mahmud (2021). Predicting Bond Strength of Steel Reinforcement in Self-Compacting Concrete (SCC) Using Adaptive Neuro-Fuzzy Inference System (ANFIS). Civil Engineering and Architecture, 9(6), 1717-1726. DOI: 10.13189/cea.2021.090605.

Copyright $\bigcirc 2021$ by authors, all rights reserved. Authors agree that this article remains permanently open access under the terms of the Creative Commons Attribution License 4.0 International License

\begin{abstract}
The advantages of using self-compacting concrete (SCC) are reducing the time of construction and the number of employments, reducing noise that can disturb the surrounding environment, and increasing the density of hardened concrete structural elements, automatically affecting bond strength reinforcement in SCC. The bond strength is a parameter as an essential factor affecting the behavior of reinforced concrete. In this manuscript, the Adaptive Neuro-Fuzzy Inference System (ANFIS) model was built to predict the bond strength in SCC. For showing the performance of the ANFIS model, the level of accuracy-based correlation coefficient $\left(R^{2}\right)$ and Root Mean Square Error (RMSE) were determined. Learning process data consists of input and output. The input in this study includes compressive strength of concrete $\left(\mathrm{f}_{\mathrm{c}}\right)$, the diameter of steel reinforcement $\left(\mathrm{d}_{\mathrm{b}}\right)$, and development of length $\left(L_{d}\right)$, while the output bond strength $(\tau)$. The results of the proposed model were in good agreement with the experimental results, as evidenced by an $\mathrm{R}^{2}$ of 0.71 and an RMSE of $3.31 \mathrm{MPa}$ in the testing data, indicating that the proposed ANFIS model is capable of accurately predicting steel reinforcement bond strength in SCC.
\end{abstract}

Keywords Bond Strength, Steel Reinforcement, SCC, ANFIS

\section{Introduction}

In reinforced concrete structures, the bond strength between steel reinforcement and concrete is as important as the compressive strength of concrete and one of the essential factors affecting the behavior of reinforced concrete elements, especially when experiencing cracks. The crack width and deflection are strongly influenced by the bond stress distribution along with the reinforcement and the slip between the steel reinforcement and the surrounding concrete [1]. The bond strength between reinforcement and concrete is influenced by many factors, some of them are compressive strength of concrete, diameter reinforcement, and development length [2].

With the development of concrete technology in the 1980s, Japanese researchers introduced self-compacting concrete (SCC) by producing a prototype that was quite successful in 1988. Self-compacting concrete is an innovative concrete that does not require vibration for placing and compaction. It can flow under its weight, completely filling formwork and achieving full compaction, even in the presence of congested reinforcement. The advantages of using SCC are reducing the time of construction and the number of employments, reducing noise that can disturb the surrounding environment, and increasing the density of hard concrete structural elements, where automatically affect bond strength reinforcement in SCC $[3,4,5]$. 
The development of soft computing, especially in artificial intelligence, allows computer machines to be able to solve problems like those done by humans. Some of the artificial intelligence that has been applied in the field of civil engineering is artificial neural networks (ANN), fuzzy logic (FL), and a combination of ANN and FL called Adaptive Neuro-Fuzzy Inference System or ANFIS. For example, Kohoutkova et al. [6] were conducted the fuzzy logic (FL) model to predict the stress-strain curve of fiber concrete. The FL and ANN model is also used to predict the compressive strength of SCC [7, 8]. Furthermore, Neshat et al. [9], Amani and Moeini [10], Mohammadhassani et al. [11] were applied ANFIS and FL models to analyze a concrete design mix, predicting strength shear reinforced concrete beam and high deflection beam.

The ANN method to predict the bond strength of conventional concrete has been carried out by Makni et al. [12]. The results of the study show that the experimental results have a good correlation with the ANN model. In addition, when compared to existing empirical formulas, the ANN model has good accuracy. Golafshani et al. [13] also stated that the ANN and FL methods effectively predict bond strength in conventional concrete. However, the use of the ANN method has several weaknesses, namely that it takes a lot of iterations in the training process to process large neural networks so that sometimes the results obtained are less accurate, while the weakness of the fuzzy logic (FL) method requires an optimization method, namely by trial and error, in determining the membership function to obtain the optimal membership function. Therefore by combining the ANN and FL methods, namely the Adaptive Neuro-Fuzzy Inference System or abbreviated as ANFIS method where the membership function and rules (IF-THEN) can be determined from input data automatically through the learning process, so this model is expected to reduce the weaknesses of each method so that the resulting predictions will be more accurate. In this manuscript, the ANFIS method has been used for predicting the bond strength in SCC. For showing the performance of the ANFIS model, the level of accuracy-based correlation coefficient $\left(\mathrm{R}^{2}\right)$ and Root Mean Square Error (RMSE) were determined.

\section{Theory of Adaptive Neuro-Fuzzy Inference System (ANFIS)}

ANFIS was first introduced by Jang [14], is a combination of Artificial Neural Network (ANN) and Fuzzy Inference System (FIS) uses the Takagi and Sugeno, model. By using a hybrid learning procedure combination of the Backward-Propagation Gradient Descent (BPGD) method and Least-Squares Estimator (LSE), the ANFIS model can build a mapping input and output which are both based on human knowledge with fuzzy rules IF THEN with the proper membership function. ANFIS's basic structure is shown in Figure 1.

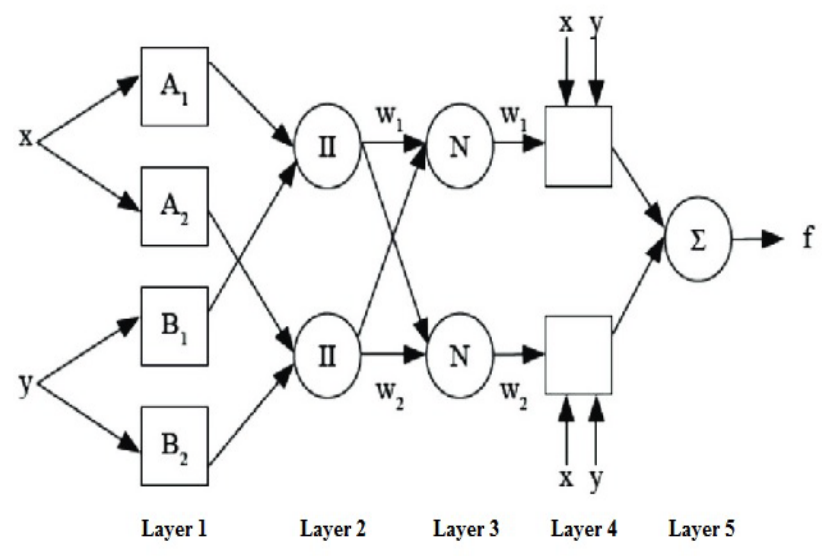

Figure 1. ANFIS Basic Structure [14]

The ANFIS system consists of five network layers that describe multi-layered neural networks (NN) and have distinctive functions for each layer, where consists of several nodes represented by squares or circles. The box symbol represents an adaptive node, meaning that the parameter value can change with learning and the circle symbol represents a non-adaptive node whose value is fixed. The functions and equations of each layer are described as follows:

\section{Layer 1: Fuzzification Layer}

The function is to generate membership degrees. This layer is called the input layer. The nodes of this layer will be connected to the fuzzy membership values

$$
\begin{aligned}
O_{1 . i}=\mu_{A i}(x) \text { for } \mathrm{i} & =1,2 \text { and } \\
O_{1 . i} & =\mu_{B i}(y) \text { for } \mathrm{i}=3,4
\end{aligned}
$$

with $\mathrm{x}$ dan $\mathrm{y}$ is input node $\mathrm{i}$.

\section{Layer 2: Product Layer}

Each output node represents the degree of firing strength for each fuzzy rule. This function can be extended if the premise has more than two fuzzy sets. The number of vertices in this layer shows the number of rules that are formed.

$$
O_{2 . i}=w_{i}=\mu_{A i}(x) \mu_{B i}(y), \text { for } \mathrm{i}=1,2
$$

Normalizes firing strength. The layer of each node in this layer is an adaptive node that displays the function of normalized firing strength, which is the ratio of the output of the node $i$ in the previous layer to the entire output of the previous layer, with the form of the node function:

$$
O_{3.1}=\bar{w}_{i}=\frac{w_{i}}{w_{1}+w_{2}}, \text { for } \mathrm{i}=1,2
$$

parameter $\left(\mathrm{p}_{\mathrm{i}}, \mathrm{q}_{\mathrm{i}}\right.$, dan $\left.\mathrm{r}_{\mathrm{i}}\right)$

Layer 4: Defuzzification Layer 
Calculate the output of the rule based on the consequent

$$
O_{4.1}=\bar{w}_{i} f_{i}=\bar{w}_{i}\left(p_{i} x+q_{i} y+r_{i}\right)
$$

Layer 5: The Total Output Layer

Calculates the ANFIS output signal by adding up all the incoming signals.

$$
O_{4.1}=\sum_{i} \bar{w}_{i} f_{i}=\frac{\sum_{i} w_{i} f_{i}}{\sum_{i} w_{i}}
$$

\section{Research Methodology}

In general, the ANFIS modelling process divided into three processes is training, testing, and checking. The principle of the training process is to learn about data to obtain results following the targets on the data, while the testing process is to evaluate the level of accuracy of the model that has been obtained from the training process. The ANFIS prediction model was developed by using the software ANFIS Tools in MATLAB Student Version

\section{R2014a [15].}

\subsection{Data Collection}

The ANFIS model was created utilizing data from several previous research on the bond strength test, including Zhu et al. [16]; De Almeida Filho et al. [17]; Valcuende and Parra [18]; Lachemi et al. [19]; Boel et al. [20]; Myers et al. [21]; Looney et al. [22]; Pop et al. [23] and Ngudiyono et al. [24]. The total number of data points used was 101, with 80 for training and 21 for testing. Tables 1 and 2 show the training and testing data. The data consists of the learning's input and output. The data is organized into a matrix, with the number of inputs in the column and the amount of data to be trained in the row (training). The last column in the matrix that is formed is the target data. The input in this study includes compressive strength $\left(\mathrm{f}_{\mathrm{c}}\right)$, the diameter of steel reinforcement $\left(\mathrm{d}_{\mathrm{b}}\right)$, and development of length $\left(\mathrm{L}_{\mathrm{d}}\right)$, and the output is bond strength $(\tau)$.

\begin{tabular}{|c|c|c|c|c|c|}
\hline Reference & No Data & $\begin{array}{c}\mathbf{f}_{\mathrm{c}} \\
(\mathrm{MPa})\end{array}$ & $\begin{array}{c}d_{b} \\
(\mathbf{m m})\end{array}$ & $\begin{array}{c}\mathbf{L}_{\mathrm{d}} \\
(\mathbf{m m})\end{array}$ & $\begin{array}{c}\tau \\
(\mathbf{M P a}) \\
\end{array}$ \\
\hline \multirow{12}{*}{ Zhu et al. [16] } & 1 & 47 & 12 & 120 & 13.32 \\
\hline & 2 & 47 & 12 & 120 & 13.73 \\
\hline & 3 & 47 & 12 & 120 & 13.45 \\
\hline & 4 & 47 & 20 & 120 & 9.65 \\
\hline & 5 & 47 & 20 & 120 & 10.55 \\
\hline & 6 & 47 & 20 & 120 & 11.30 \\
\hline & 7 & 79.5 & 12 & 120 & 34.08 \\
\hline & 8 & 79.5 & 12 & 120 & 32.63 \\
\hline & 9 & 79.5 & 12 & 120 & 31.02 \\
\hline & 10 & 79.5 & 20 & 120 & 26.41 \\
\hline & 11 & 79.5 & 20 & 120 & 28.83 \\
\hline & 12 & 79.5 & 20 & 120 & 32.52 \\
\hline \multirow{4}{*}{ De Almeida Filho et al. [17] } & 13 & 30 & 10 & 50 & 14.34 \\
\hline & 14 & 30 & 16 & 80 & 12.93 \\
\hline & 15 & 60 & 10 & 50 & 18.11 \\
\hline & 16 & 60 & 16 & 80 & 19.23 \\
\hline \multirow{4}{*}{ Valcuende dan Parra [18] } & 17 & 30.21 & 16 & 80 & 18.00 \\
\hline & 18 & 35.77 & 16 & 80 & 21.66 \\
\hline & 19 & 50.18 & 16 & 80 & 27.97 \\
\hline & 20 & 61.15 & 16 & 80 & 39.98 \\
\hline \multirow{6}{*}{ Lachemi et al. [19] } & 21 & 38.8 & 15 & 200 & 11.12 \\
\hline & 22 & 38.8 & 15 & 200 & 11.97 \\
\hline & 23 & 38.8 & 15 & 200 & 14.14 \\
\hline & 24 & 38.8 & 15 & 100 & 8.59 \\
\hline & 25 & 38.8 & 15 & 100 & 12.01 \\
\hline & 26 & 38.8 & 15 & 100 & 9.02 \\
\hline \multirow{6}{*}{ Boel et al. [20] } & 27 & 58 & 8 & 28 & 25.88 \\
\hline & 28 & 58 & 12 & 42 & 29.86 \\
\hline & 29 & 58 & 16 & 56 & 32.32 \\
\hline & 30 & 55.8 & 8 & 28 & 19.92 \\
\hline & 31 & 55.8 & 12 & 42 & 24.39 \\
\hline & 32 & 55.8 & 16 & 56 & 30.64 \\
\hline
\end{tabular}

Table 1. Data Training 


\begin{tabular}{|c|c|c|c|c|c|}
\hline Reference & No Data & $\begin{array}{c}\mathbf{f}_{\mathrm{c}} \\
(\mathbf{M P a})\end{array}$ & $\begin{array}{c}\mathrm{d}_{\mathrm{b}} \\
(\mathrm{mm})\end{array}$ & $\begin{array}{c}\mathbf{L}_{\mathrm{d}} \\
(\mathrm{mm})\end{array}$ & $\begin{array}{c}\tau \\
(\mathbf{M P a})\end{array}$ \\
\hline \multirow{12}{*}{ Myers et al. [21] } & 33 & 48.23 & 12.7 & 63.5 & 27.04 \\
\hline & 34 & 48.23 & 12.7 & 63.5 & 26.16 \\
\hline & 35 & 48.23 & 12.7 & 63.5 & 26.97 \\
\hline & 36 & 48.23 & 19.05 & 95.25 & 28.20 \\
\hline & 37 & 48.23 & 19.05 & 95.25 & 27.28 \\
\hline & 38 & 48.23 & 19.05 & 95.25 & 28.88 \\
\hline & 39 & 68.17 & 12.7 & 63.5 & 31.11 \\
\hline & 40 & 68.17 & 12.7 & 63.5 & 31.51 \\
\hline & 41 & 68.17 & 12.7 & 63.5 & 31.95 \\
\hline & 42 & 68.17 & 19.05 & 95.25 & 31.85 \\
\hline & 43 & 68.17 & 19.05 & 95.25 & 31.31 \\
\hline & 44 & 68.17 & 19.05 & 95.25 & 30.87 \\
\hline \multirow{30}{*}{ Pop et al. [23] } & 45 & 52.4 & 10 & 30 & 24.24 \\
\hline & 46 & 52.4 & 10 & 40 & 21.07 \\
\hline & 47 & 52.4 & 10 & 50 & 23.27 \\
\hline & 48 & 52.4 & 12 & 36 & 24.53 \\
\hline & 49 & 52.4 & 12 & 48 & 21.51 \\
\hline & 50 & 52.4 & 12 & 60 & 20.98 \\
\hline & 51 & 52.4 & 14 & 42 & 21.36 \\
\hline & 52 & 52.4 & 14 & 56 & 20.26 \\
\hline & 53 & 52.4 & 14 & 70 & 20.02 \\
\hline & 54 & 57.3 & 10 & 30 & 26.63 \\
\hline & 55 & 57.3 & 10 & 40 & 27.24 \\
\hline & 56 & 57.3 & 10 & 50 & 26.15 \\
\hline & 57 & 57.3 & 12 & 36 & 24.77 \\
\hline & 58 & 57.3 & 12 & 48 & 24.83 \\
\hline & 59 & 57.3 & 12 & 60 & 25.46 \\
\hline & 60 & 57.3 & 14 & 42 & 20.75 \\
\hline & 61 & 57.3 & 14 & 56 & 19.1 \\
\hline & 62 & 57.3 & 14 & 70 & 23.18 \\
\hline & 63 & 70.2 & 10 & 30 & 30.29 \\
\hline & 64 & 70.2 & 10 & 40 & 28.89 \\
\hline & 65 & 70.2 & 10 & 50 & 25.68 \\
\hline & 66 & 70.2 & 12 & 36 & 29.83 \\
\hline & 67 & 70.2 & 12 & 48 & 27.99 \\
\hline & 68 & 70.2 & 12 & 60 & 26.22 \\
\hline & 69 & 70.2 & 14 & 42 & 27.83 \\
\hline & 70 & 70.2 & 14 & 56 & 27.43 \\
\hline & 71 & 70.2 & 14 & 70 & 21.85 \\
\hline & 72 & 77.8 & 10 & 50 & 28.63 \\
\hline & 73 & 77.8 & 12 & 60 & 26.03 \\
\hline & 74 & 77.8 & 14 & 70 & 27.38 \\
\hline \multirow{6}{*}{ Ngudiyono et al. [24] } & 75 & 35.5 & 10 & 100 & 17.88 \\
\hline & 76 & 35.5 & 10 & 100 & 16.58 \\
\hline & 77 & 35.5 & 12 & 100 & 18.60 \\
\hline & 78 & 35.5 & 12 & 100 & 19.81 \\
\hline & 79 & 35.5 & 16 & 100 & 14.67 \\
\hline & 80 & 35.5 & 16 & 100 & 15.86 \\
\hline
\end{tabular}


Table 2. Data testing

\begin{tabular}{|c|c|c|c|c|c|}
\hline Reference & No Data & $\begin{array}{c}\mathrm{f}_{\mathrm{c}} \\
(\mathrm{MPa})\end{array}$ & $\begin{array}{c}\mathrm{d}_{\mathrm{b}} \\
(\mathrm{mm})\end{array}$ & $\begin{array}{c}\begin{array}{c}\mathrm{L}_{\mathrm{d}} \\
(\mathrm{mm})\end{array} \\
\end{array}$ & $\begin{array}{c}\tau \\
(\mathrm{MPa}) \\
\end{array}$ \\
\hline \multirow{6}{*}{ Boel et al. [20] } & 1 & 58 & 8 & 28 & 25.88 \\
\hline & 2 & 58 & 12 & 42 & 29.86 \\
\hline & 3 & 58 & 16 & 56 & 32.20 \\
\hline & 4 & 55.8 & 8 & 28 & 19.92 \\
\hline & 5 & 55.8 & 12 & 42 & 24.39 \\
\hline & 6 & 55.8 & 16 & 56 & 30.64 \\
\hline \multirow{12}{*}{ Looney et al. [22] } & 7 & 47.2 & 13 & 64 & 26.30 \\
\hline & 8 & 47.2 & 13 & 64 & 25.40 \\
\hline & 9 & 47.2 & 13 & 64 & 26.20 \\
\hline & 10 & 47.2 & 19 & 89 & 30.30 \\
\hline & 11 & 47.2 & 19 & 89 & 29.30 \\
\hline & 12 & 47.2 & 19 & 89 & 31.00 \\
\hline & 13 & 67.2 & 13 & 64 & 30.30 \\
\hline & 14 & 67.2 & 13 & 64 & 30.60 \\
\hline & 15 & 67.2 & 13 & 64 & 31.10 \\
\hline & 16 & 67.2 & 19 & 89 & 34.20 \\
\hline & 17 & 67.2 & 19 & 89 & 33.70 \\
\hline & 18 & 67.2 & 19 & 89 & 33.20 \\
\hline \multirow{3}{*}{ Ngudiyono et al. [24] } & 19 & 35.5 & 10 & 100 & 12.87 \\
\hline & 20 & 35.5 & 12 & 100 & 20.92 \\
\hline & 21 & 35.5 & 16 & 100 & 15.30 \\
\hline
\end{tabular}

\subsection{Performance ANFIS Model}

The suggested ANFIS model reliability or accuracy level was determined by utilizing Equation 6 to calculate the error value with the Root Mean Square Error (RMSE) and Equation 7 to calculate the correlation coefficient $R^{2}$.

$$
\begin{gathered}
R M S E=\sqrt{\frac{\sum_{i=1}^{n}\left(t_{i}-y_{i}\right)^{2}}{n}} \\
R^{2}=1-\frac{\sqrt{\sum_{i=1}^{n}\left(t_{i}-y_{i}\right)^{2}}}{\sqrt{\sum_{i=1}^{n}\left(t_{i}-\bar{t}\right)^{2}}}
\end{gathered}
$$

where:

$\mathrm{t}_{\mathrm{i}}=$ experiment data $\mathrm{i}$

$\mathrm{y}_{\mathrm{i}}=$ ANFIS model data $\mathrm{i}$

$\bar{t}=$ average experiment data

$\mathrm{n}=$ number of data

\section{Result and Discussion}

\subsection{Development ANFIS Model}

The Adaptive Neuro-Fuzzy Inference System (ANFIS) is a hybrid of ANN and FIS in which membership functions and rules IF THEN are automatically determined from data input through a learning process [15]. Figure 2 and Figure 3 depict the FL and ANN Architect models, respectively. The ANFIS toolbox MATLAB Student Version program provides multiple membership functions for inputs: trimf, trapmf, gbellmf, gaussmf, gauss $2 \mathrm{mf}$, pimf, dsigmf, and psigmf [15]. Figure 4 to 6 demonstrate the gaussmf membership function of the FIS model for input data, which are compressive strength $\left(\mathrm{f}_{\mathrm{c}}\right)$, the diameter of steel reinforcement $\left(\mathrm{d}_{\mathrm{b}}\right)$, and development of length $\left(\mathrm{L}_{\mathrm{d}}\right)$, and Figure 7 shows the rule IF THEN. From the Figure 4 to 6 showed that range of the compressive strength $\left(\mathrm{f}_{\mathrm{c}}\right)$ class between $30 \mathrm{MPa}$ to 79.5 $\mathrm{MPa}$, the diameter of steel reinforcement $\left(\mathrm{d}_{\mathrm{b}}\right)$ between 8 $\mathrm{mm}$ to $20 \mathrm{~mm}$, and the development of length $\left(\mathrm{L}_{\mathrm{d}}\right)$ between $28 \mathrm{~mm}$ to $200 \mathrm{~mm}$. 
A < Student Version $>$ : FIS Editor: Model

File Edit View

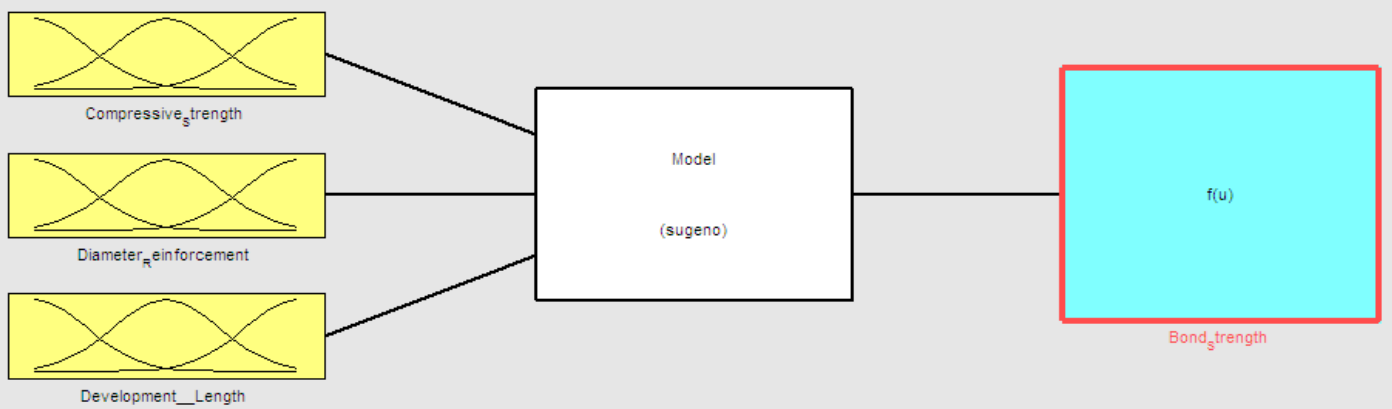

\begin{tabular}{|lll}
\hline FIS Name: & Model & FIS Type: \\
& & sugeno \\
\hline
\end{tabular}

\begin{tabular}{|c|c|c|c|c|}
\hline And method & prod & $\checkmark$ & Current Variable & \\
\hline Or method & probor & - & Name & Bond_Strength \\
\hline \multirow{2}{*}{ Implication } & & & Type & output \\
\hline & & & Range & [8.59 39.98] \\
\hline Aggregation & $\max$ & $\nabla$ & & \\
\hline Defuzzification & wtaver & - & Help & Close \\
\hline
\end{tabular}

System "Moder": 3 inputs, 1 output, and 216 rules

Figure 2. FIS Model

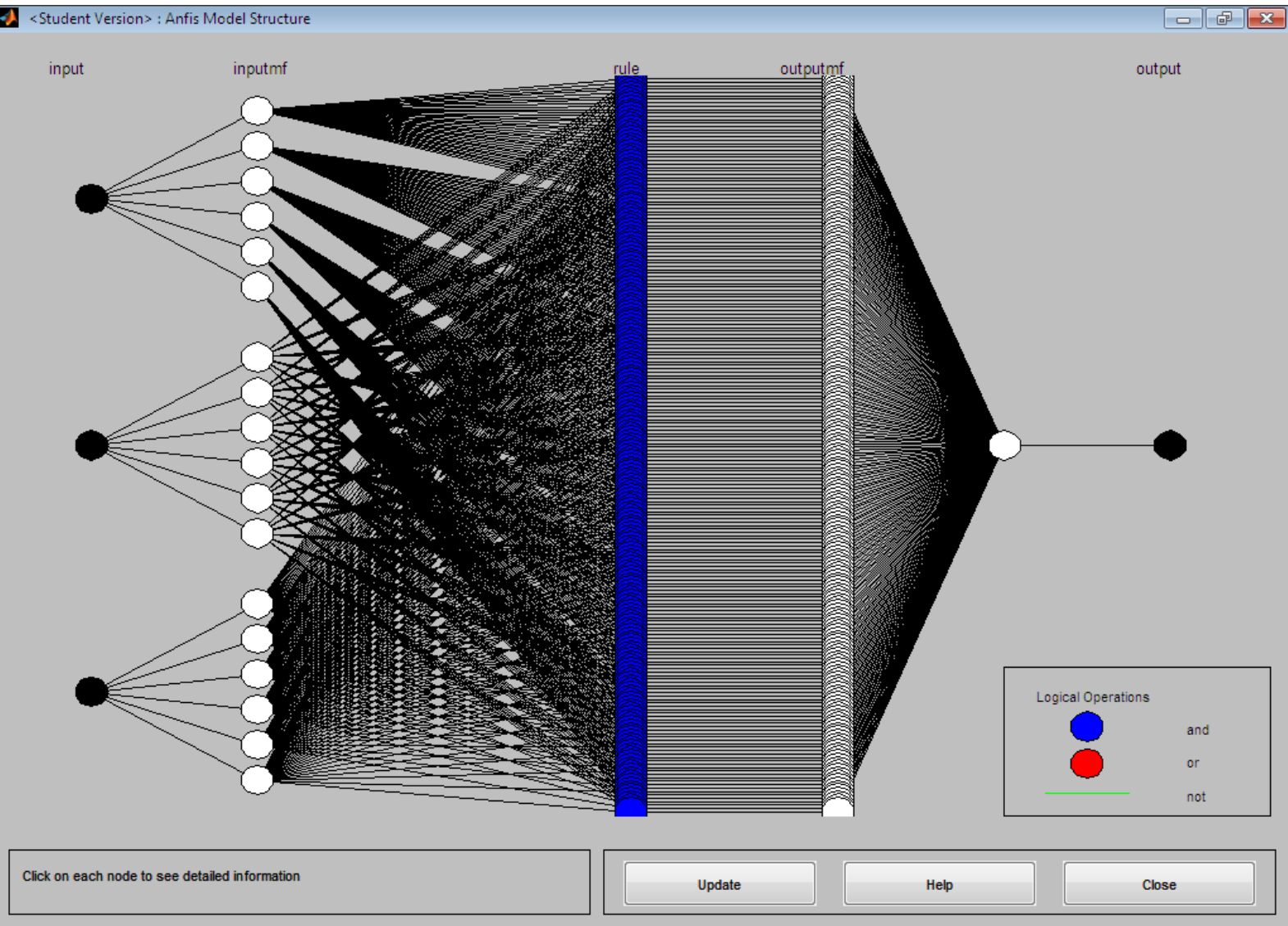

Figure 3. ANN Architect model 
< <tudent Version> : Membership Function Editor: Model

File Edit View
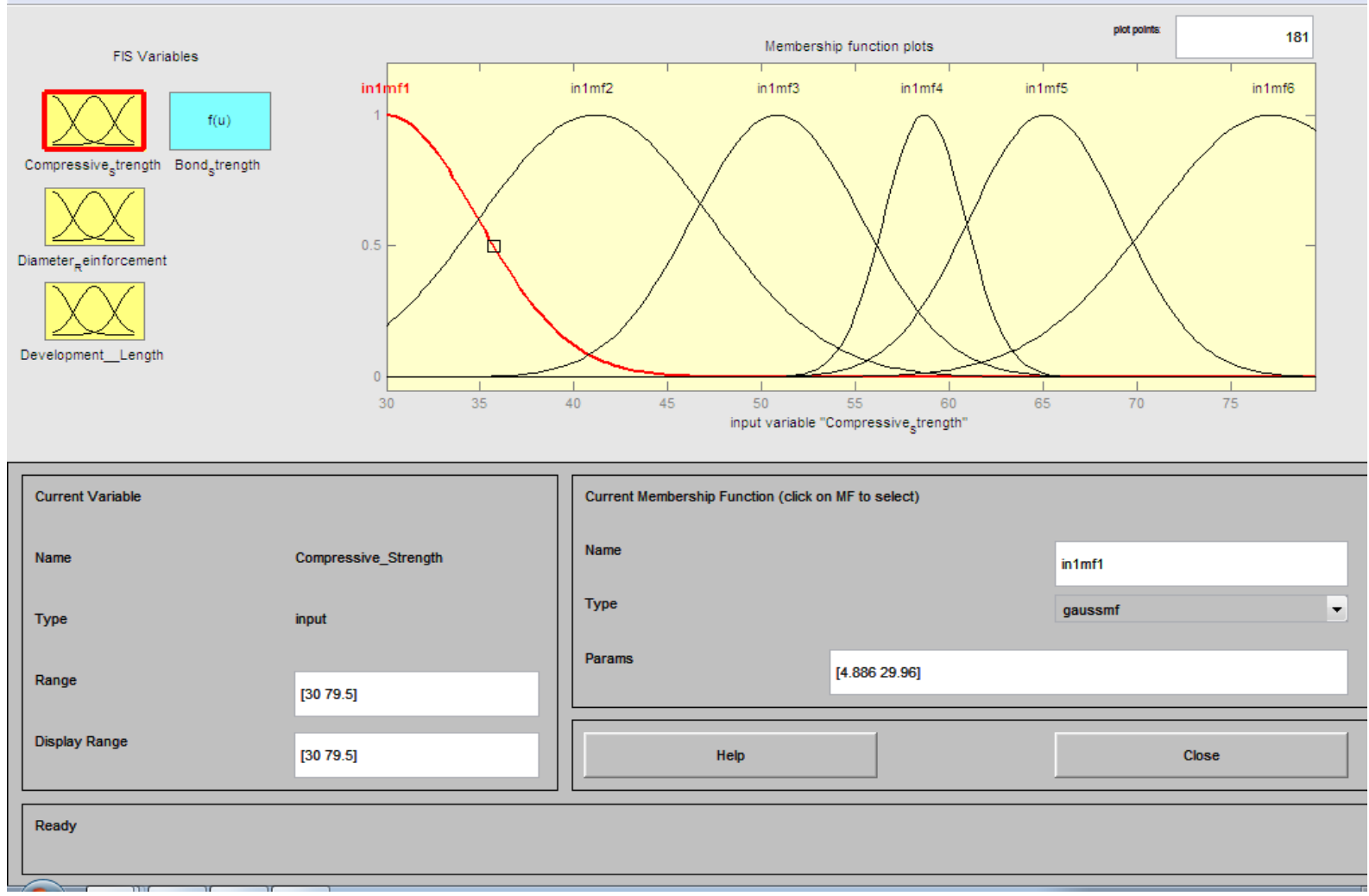

Figure 4. Membership function compressive strength ( $\left.\mathrm{f}^{\prime} \mathrm{c}\right)$

<Student Version> : Membership Function Editor: Model

D回

File Edit View
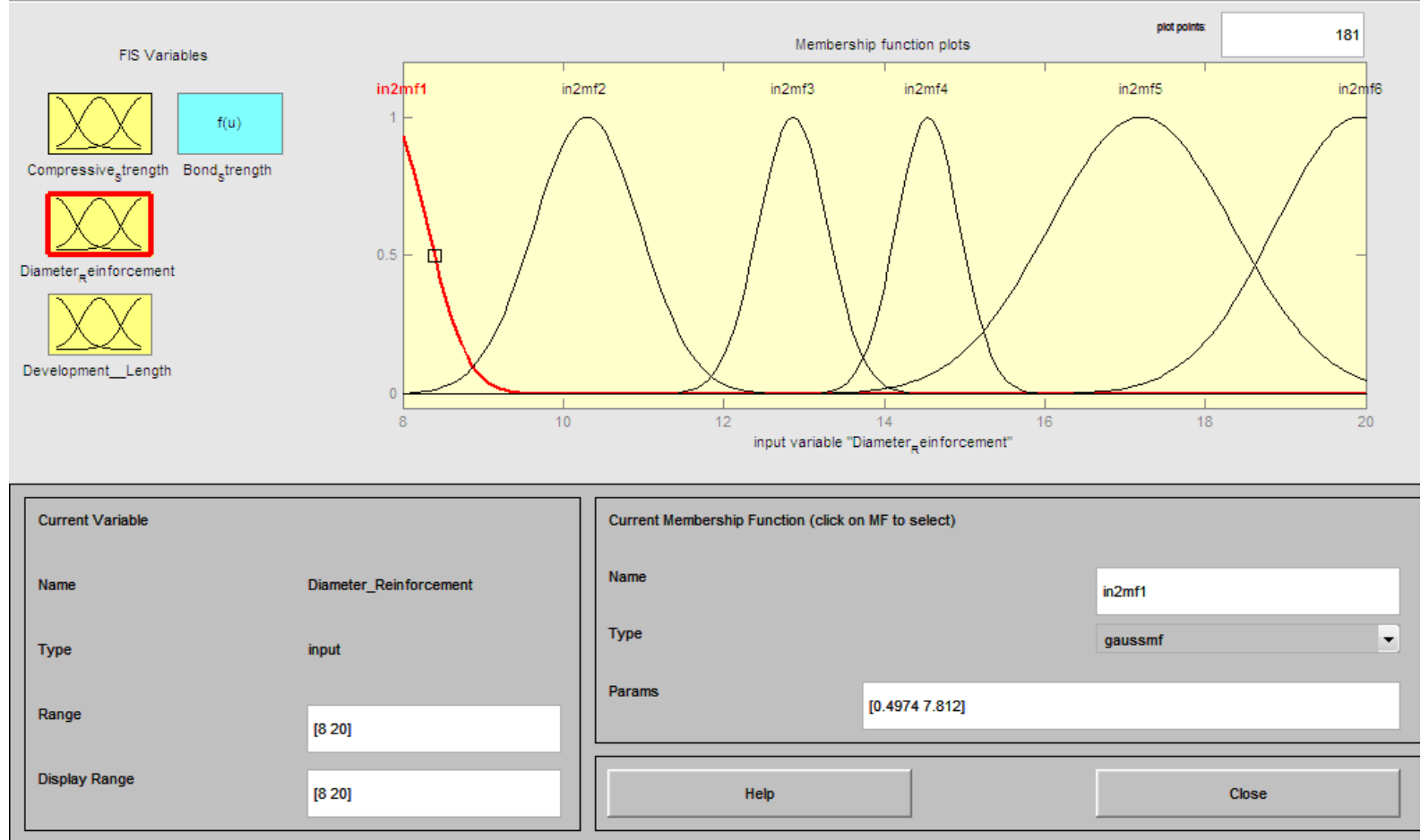

Selected variable "Diameter_Reinforcement"

Figure 5. Membership function the diameter of steel reinforcement $\left(d_{b}\right)$ 
$1<$ <tudent Version > : Membership Function Editor: Model

File Edit View

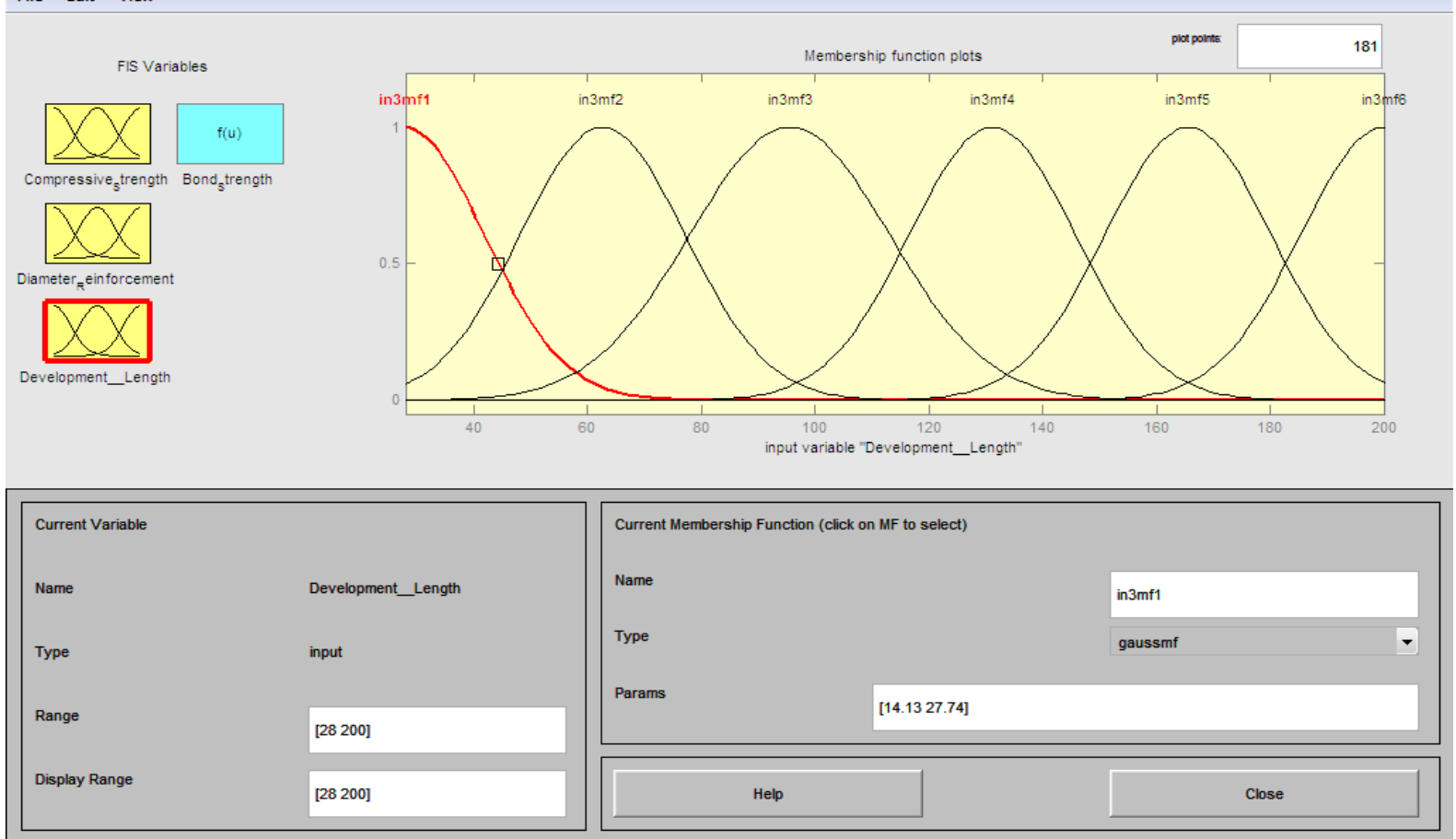

Selected variable "Development_Length"

Figure 6. Membership function development of length $\left(\mathrm{L}_{\mathrm{d}}\right)$

<Student Version> : Rule Viewer: Model

File Edit View Options

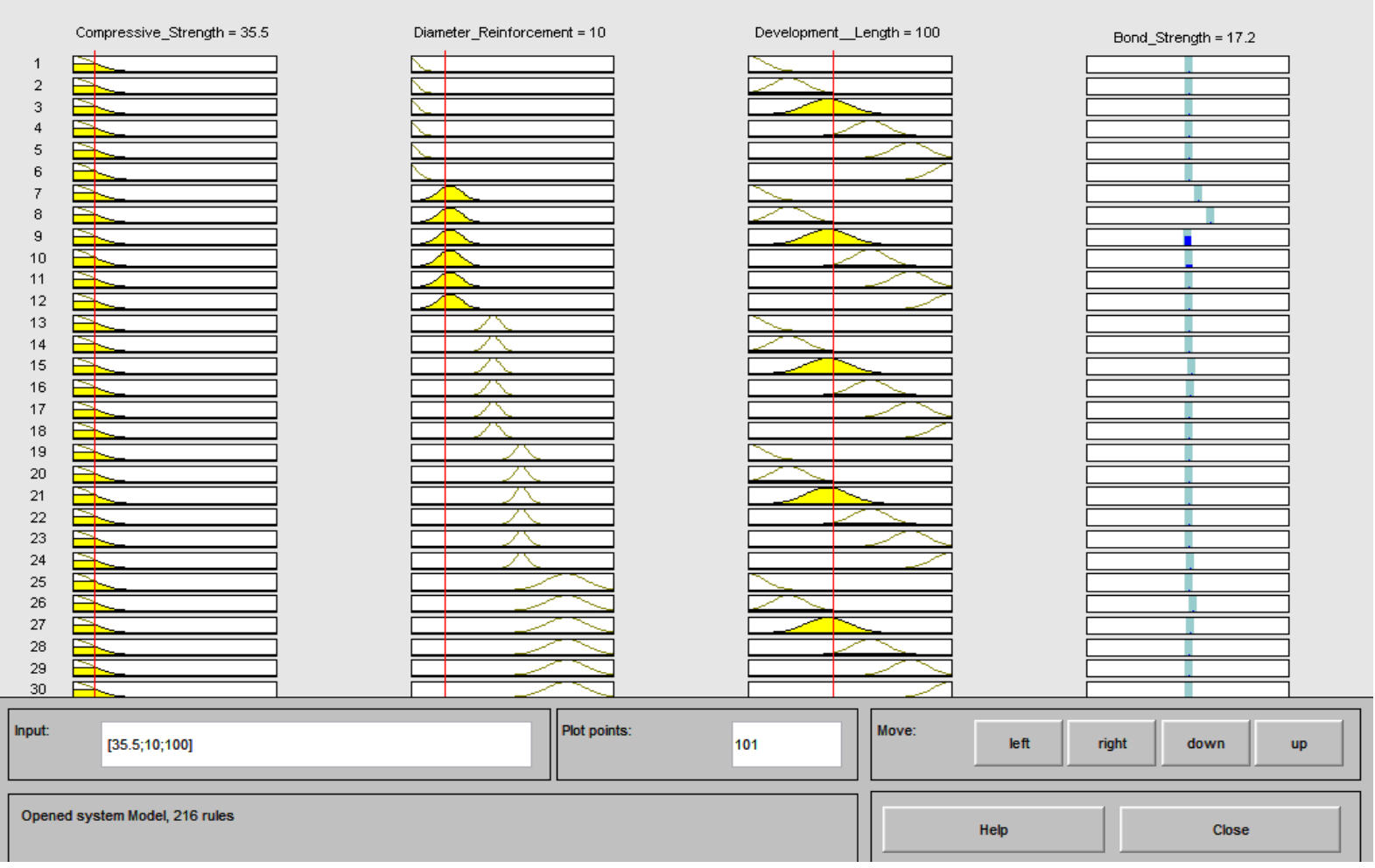

Figure 7. Rule IF THEN ANFIS model 


\subsection{Evaluation ANFIS Model}

The results of the learning process were compared to the testing data to evaluate the performance of the constructed ANFIS model, as shown in Figures 8 and 9. The correlation coefficient $\left(\mathrm{R}^{2}\right)$ for testing data is 0.71 with RMSE $3.31 \mathrm{MPa}$, indicating that the ANFIS model has a good level of accuracy. When viewed from the distribution data with a diagonal line reference, both figures clearly indicate that the distribution of data above and below the diagonal line is largely identical (mark line forming an angle of $45^{\circ}$ ). This implies that the suggested ANFIS model predicts steel reinforcement bond strength in self-compacting concrete (SCC) accurately.

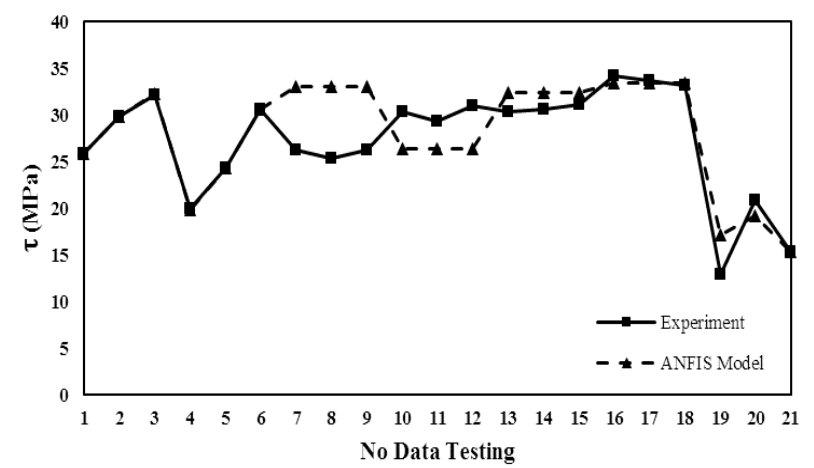

Figure 8. Comparison of the bond strength experiment and ANFIS model

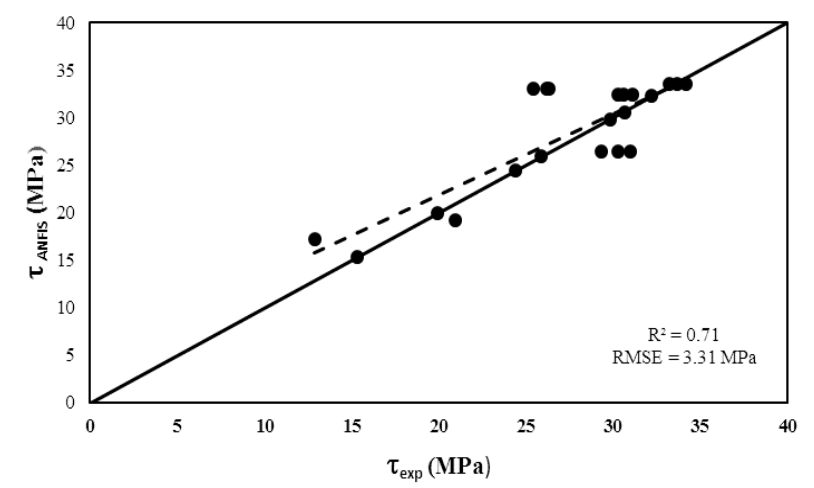

Figure 9. Comparison of the bond strength experiment and ANFIS model

\section{Conclusions}

According to the experimental from several previous research as training and testing data and ANFIS model above, some conclusion remark can be obtained as follow:

(1) The bond strength between steel reinforcement and self-compacting concrete (SCC) depending on parameters compressive strength $\left(\mathrm{f}^{\prime} \mathrm{c}\right)$, the diameter of steel reinforcement $\left(\mathrm{d}_{\mathrm{b}}\right)$, and development of length $\left(\mathrm{L}_{\mathrm{d}}\right)$.

(2) ANFIS model was created in this study, the gaussmf membership function of the FIS model for input data compressive strength $\left(f^{\prime} c\right)$, the diameter of steel reinforcement $(\mathrm{db})$, and development of length (Ld) successfully to estimate the bond strength of steel reinforcement in self-compacting concrete (SCC).

(3) The ANFIS proposed model was in good agreement with the experimental results, as evidenced by an $\mathrm{R}^{2}$ of 0.71 and an RMSE of $3.31 \mathrm{MPa}$ in the testing data, indicating that the proposed ANFIS model is capable of accurately predicting steel reinforcement bond strength in self-compacting concrete (SCC).

\section{Acknowledgments}

The authors would like gratefully to thank the University of Mataram's having been financial support from DIPA BLU (PNBP) with research contract No: 2700/UN.18.L1/PP/2020.

\section{REFERENCES}

[1] Desnerck, P., Schutter, G. D., Taerwe, L., A Local Bond Stress-Slip Model for Reinforcing Bars in Self-Compacting Concrete, Fracture Mechanics of Concrete and Concrete Structures - Assessment, Durability, Monitoring and Retrofitting of Concrete Structures, Korea Concrete Institute, Seoul, 2010.

[2] El-Hacha, R., EI-Agroudy, H., RizkalJa, S. H., Bond Characteristics of High-Strength Steel Reinforcement, ACI Structural Journal, Vol. 103, No, 6, 771-781, 2006.

[3] Okamura, H. dan Ouchi, M., Self-Compacting Concrete, Journal of Advanced Concrete Technology, Vol. 1 No. 1, April, 5-15, 2003.

[4] European Guidelines for Self-Compacting Concrete: Specification, Production and Use, European Project Group, 2005

[5] S.Vijaya Kumar, B.Dean Kumar, B L P Swami, "Effect of Metakaolin and Condensed Silica Fume on the Rheological and Structural Properties of Self-compacting Concrete," Civil Engineering and Architecture, Vol. 8, No. 5, pp. 1057 - 1062, 2020. DOI: 10.13189/cea.2020.080532

[6] Kohoutkova, A., Stemberk, P., Pokorna, N., Fuzzy Logic Model of Fiber Concrete, Fracture Mechanics of Concrete and Concrete Structures - Assessment, Durability, Monitoring and Retrofitting of Concrete Structures, Korea Concrete Institute, Seoul, 2010.

[7] Paratibha., A dan Yogesh, A., Prediction of Compressive Strength of Self-Compacting Concrete with Fuzzy Logic, World Academy of Science Engineering and Technology, Vol. 5, 745-752, 2011.

[8] Raheman, A., dan Modani, P.O., Prediction of Properties of Self-Compacting Concrete Using Artificial Neural Network, International Journal of Engineering Research and Application, Vol. 3, Issue. 4, Jul-Aug, 333-339, 2013. 
[9] Neshat, M., Adeli, A., Masoumi, A., Sargolzae, M., A Comparative Study on ANFIS and Fuzzy Expert System Models for Concrete Mix Design, IJCSI International Journal of Computer Science Issues, Vol. 8, No. 2, 196-210, 2011.

[10] Amani, J., dan Moeini, R., Prediction of Shear Strength of Reinforced Concrete Beam Using Adaptive Neuro-Fuzzy Inference System and Artificial Network, Scientia Iranica Journal, Vol. 19, No. 2, 242-248, 2012.

[11] Mohammadhassani, M., Pour, H. N., Jumaat, M. Z., Jamel, M., Hakim, S. J. S., Application of the ANFIS model in Deflection Prediction of Concrete Deep Beam, Structural Engineering and Mechanics, Vol. 45, N0. 3, 319-332, 2013.

[12] Makni, M., Daoud, A., Karray, M. A., Application of Artificial Neural Network technique in Civil Engineering, Proceedings International Conference on Control, Engineering \& Information Technology (CEIT'13), Vol. 2, 56-61, 2013.

[13] Golafshani, E., M., Rahai, A., Sebt, M., H., Akbarpour, H., Prediction of bond strength of spliced steel bars in concrete using artificial neural network and fuzzy logic, Construction and Building Materials 36, 411-418, 2012.

[14] Jang, J.S.R., ANFIS: Adaptive-Network-Based Fuzzy Inference System, IEEE Transactions on Systems, Man, and Cybernetics, Vol. 23, No. 3, 1993.

[15] MATLAB, Neuro-Adaptive Learning, and ANFIS,https://www.mathworks.com/help/fuzzy/neuro-ada ptive-learning-and-anfis.html, 2014.

[16] Zhu, W., Sonebi, M., Bartos, P. J. M., Bond and interfacial properties of reinforcement in self-compacting concrete, Mater Struct: 37(7), 442-448, 2004.
[17] De Almeida Filho. F. M., Mounir, K., El Debs, A. L. H. Bond-slip behavior of self-compacting concrete and vibrated concrete using the pull-out and beam tests, Mater Struct: 41(6):1073-1089, 2008.

[18] Valcuende, M., Parra, C., Bond behavior of reinforcement in self-compacting concretes. Constr Build Mater: 23(1), 162-170, 2009.

[19] Lachemi, M., Bae, S., Hossain, K. M. A., Sahmaran, M., 2009, Steel-concrete bond strength of lightweight self-consolidating concrete. Mater Structure: 42(7), 10151023, 2009.

[20] Boel, V., Helincks, P., Desnerck, P., De Schutter, G., Bond behavior and shear capacity of self-compacting concrete. In: Design, production, and placement of self-consolidating concrete, Springer, 343-353, 2010.

[21] Myers, J. J., Volz, J. S., Sells, E, Self-consolidating concrete (SCC) for infrastructure elements, No. NUTC R265, 2012

[22] Looney, T., Arezoumandi, M., Volz, J., S., Myers, J. J., An Experimental Study on Bond Strength of Reinforcing Steel in Self-Consolidating Concrete, International Journal of Concrete Structures and Materials Vol.6, No.3, 187-197, 2012

[23] Pop, I., De Schutter, G., Desnerck, P., Onet, T., Bond between powder type self-compacting concrete and steel reinforcement. Constr Build Mater 41, 824-833, 2013.

[24] Ngudiyono, Merdana, I. N., Mahmud, F., Fajrin, J., The Application Adaptive Neuro-Fuzzy Inference System (ANFIS) to Predict Bond Strength of the Steel Reinforcement in Self-Compacting Concrete (SCC), Final Report, Research Institutions and Community Service, University of Mataram, 2020. 